\title{
Controle da mancha angular do feijoeiro com uso de fungicidas e seu efeito na produção das plantas
}

\author{
Control of angular leaf spot on dry beans with fungicides and its effect \\ on plant production
}

\author{
Luís Alfredo Rauer Demant ${ }^{1}$, Antonio Carlos Maringoni ${ }^{2 *}$
}

\section{RESUMO}

A mancha angular, causada por Phaeoisairopsis griseola, é uma doença de grande importância para a cultura do feijoeiro no Brasil. Em condições climáticas propícias, cultivares suscetíveis apresentam perdas significativas devida a doença. O uso de fungicidas é um mecanismo fundamental para o manejo da mancha angular nestas condições. O presente trabalho teve por objetivos: a) verificar a ação de alguns fungicidas sobre alterações fisiológicas de plantas de feijoeiro (índices de fotossíntese líquida e condutividade estomática); b) avaliar a eficácia de alguns fungicidas registrados para a cultura no controle da mancha angular; c) analisar a influência dos mesmos sobre alguns parâmetros agronômicos (massa de 100 grãos, número de grãos por vagem e número de vagens por plantas) do feijoeiro cultivar Pérola. Para tanto, quatro ensaios foram conduzidos, dois em condições de telado e dois ensaios sob condições de campo. Foi constatado que a pulverização de piraclostrobina, tebuconazole e tebuconazole + trifloxistrobina elevou os níveis de fotossíntese, porém não alterou a condutância estomática das plantas. A pulverização dos fungicidas tebuconazole, piraclostrobina, metiram + piraclostrobina e azoxistrobina proporcionaram os melhores níveis de controle da doença e também os maiores valores de massa de 100 grãos, com exceção da azoxistrobina para este parâmetro.

Palavras chave: Phaseolus vulgaris L., Phaeoisairopsis griseola, controle químico.

\begin{abstract}
The angular leaf spot of dry bean caused by the fungus Phaeoisairopsis griseola is a very important disease on dry bean crops in Brazil. In propitious weather conditions, susceptible cultivars have significant losses due to this disease. In these conditions, fungicide usage is an important step for angular leaf spot management. Since the effects of this method of control on plant physiology are not known, this study had the following objectives: a) Verify the action of fungicide in physiological changes in dry beans (photosynthesis rate and stomatal conductivity); b) evaluate the efficacy of some fungicides for the control of angular leaf spot; and c) examine the effects of these fungicides on other agronomic parameters; weight of 100 grains, number of grains per pod and number of pods per plant. The dry bean cultivar used in this study was Perola. Four trials were conducted, two in a net greenhouse and two trials under field conditions. A spray of piraclostrobin, tebuconazol and tebuconazol+ trifloxistrobin increased photosynthesis rates, although stomatal conductivity was not changed. In addition, sprays of tebuconazol, piraclostrobin, metiram+piraclostrobin and azoxistrobin provided better levels of disease control and also higher weight of 100 grains, with the exception of azoxystrobin for this parameter.
\end{abstract}

Palavras chave: Phaseolus vulgaris L., Phaeoisairopsis griseola, chemical control.

\section{Introdução}

O feijoeiro comum (Phaseolus vulgaris L.) é a espécie mais cultivada entre as demais do gênero Phaseolus. Considerando todos os gêneros e espécies de Phaseolus, estatísticas da FAO publicadas em 2010, evidenciaram que a produção mundial de feijão situa - se ao redor de 19,7 milhões de toneladas, ocupando uma área de 25,2 milhões de hectares. As Américas respondem por 37,9\% do consumo mundial, seguido da Ásia (42,8\%), África $(17,2 \%)$, Europa $(1,9 \%)$ e Oceania $(0,2 \%)$. Os países

1 Du Pont do Brasil S.A., Rua Bortolo Ferro, 500 A - Poço Fundo, 13140-000, Paulínia - SP, Brasil, fone (0xx15) 33427363. Email: Luis.A.Demant@bra.dupont.com

2 UNESP/Faculdade de Ciências Agronômicas/Departamento de Produção Vegetal, 18603-970, Botucatu-SP, Brasil, fone (0xx14)38807475. Email: maringoni@fca.unesp.br

* Autor para correspondencia. 
em desenvolvimento são responsáveis por $86,7 \%$ do consumo mundial. Aproximadamente $66 \%$ da produção mundial foi proveniente de sete países, sendo o Brasil o maior produtor, responsável por 17\% da produção mundial (Faostat, 2010) .

As doenças encontram - se entre os fatores mais importantes associadas à baixa produtividade do feijoeiro comum no Brasil, as quais podem reduzir significativamente a produção da cultura (Del Peloso et al., 2003). Entre as doenças fúngicas de grande importância desta cultura no Brasil pode - se destacar a mancha angular, causada por Phaeoisariopsis griseola. Estratégias de controle para a doença incluem práticas culturais, controle químico e resistência genética. Este patógeno apresenta alta variabilidade na patogenicidade o que pode dificultar a durabilidade da resistência genética nas cultivares (Sartorato, 2004). Em determinadas condições, o plantio de cultivares suscetíveis e ambiente propício para o desenvolvimento de epidemia faz - se necessária a adoção do controle químico na parte aérea das plantas. No Brasil há o registro de 85 fungicidas (produtos comercias) empregados no controle da mancha angular, destacando - se os grupos dos benzimidazóis, ditiocarbamatos, inorgânicos (cobre e estanho), estrobilurinas, triazóis e algumas misturas desses grupos (Agrofit, 2011).

Conforme relatos de alguns trabalhos como os de Kendra (2009), na Índia, evidenciaram a eficácia do controle da mancha angular com a pulverização de hexaconazole, propiconazole, mancozebe, difenoconazole e carbendazim, porém baixa eficácia com propinebe. Já Barros et al. (2000) verificaram que a mistura de tanque de fungicidas fluquinconazole e hidróxido de fentina, azoxystrobim e clorotalonil, tetraconazole e tiofanato metílico mostraram boa eficácia no controle de mancha angular. Também Ito et al. (2000) evidenciaram a mistura de hidróxido de fentina e fluquinconazole, além de azoxystrobina e a mistura de imibenconazole e hidróxido de fentina no controle da doença. Rava (2002) constatou elevada eficiência de epoxiconazole, sozinho ou em misturas, e de piraclostrobina, em três doses e em mistura com epoxiconazole no controle da doença. $\mathrm{O}$ efeito do piraclostrobina foi significativamente superior ao efeito dos produtos azoxystrobina, tebuconazole e tiofanato metílico + clorotalonil. Outros tratamentos de mistura de produtos propostos por Rava (2006) são: protioconazole + trifloxistrobina e trifloxistrobina + tebuconazole.
A piraclostrobina, fungicida do grupo das estrobirulinas, tem apresentado efeito fisiológico em plantas de soja, que além do controle de doenças, principalmente a ferrugem asiática, causa alterações nas plantas que levam a um aumento na produtividade devida às maiores taxas de fotossíntese líquida, maior massa seca total, maior área foliar, maior teor de clorofila e maior atividade da enzima nitrato redutase, que além de favorecer a redução da respiração e da síntese de etileno, minimiza as perdas por déficit hídrico (Fagan, 2007; Rodrigues et al., 2009; Fagan et al., 2010).

O presente trabalho teve por objetivos avaliar a ação de alguns fugicidas no controle da mancha angular, na alteração de alguns parâmetros fisiológicos (fotossíntese líquida e condutância estomática) e na produção de plantas de feijoeiro cultivar Pérola.

\section{Material e Métodos}

Dois ensaios foram conduzidos sob condições de telado junto ao Departamento de Produção Vegetal - Defesa Fitossanitária, da Faculdade de Ciências Agronômicas/UNESP, no período de março a maio (ensaio 1) e setembro a novembro (ensaio 2) de 2010, para avaliar a ação dos fungicidas sobre alguns parâmetros fisiológicos de plantas de feijoeiro cultivar Pérola, e dois ensaios sob condições de campo, em 2007 e 2009, com a mesma cultivar de feijoeiro, visando avaliar o controle da mancha angular.

Para os ensaios conduzidos em telado, as plantas de feijoeiro da cultivar Pérola foram obtidas em vasos contendo $10 \mathrm{~L}$ substrato devidamente adubado e cada parcela experimental foi representada por um vaso, contendo três plantas cada, no delineamento experimental de blocos ao caso, com oito tratamentos e seis repetições. Os tratamentos ensaiados foram: azoxistrobina $-60 \mathrm{~g} \cdot \mathrm{ha}^{-1}$, metiran + piraclostrobina $-825+75$ g.ha $^{-1}$, piraclostrobina -75 g.ha $^{-1}$, trifloxistrobina - 150 g.ha ${ }^{-1}$, tebuconazole - 40 g.ha $^{-1}$, hidróxido de fentina - 330 g.ha ${ }^{-1}$, tebuconazole + trifloxistrobina $-150+75$ g.ha $^{-1}$ e testemunha (água). Os produtos foram aplicados aos 30, $45 \mathrm{e}$ 60 dias após a emergência das plantas, com um pulverizador costal pressurizado $\left(\mathrm{CO}_{2}\right)$, equipado com três pontas tipo jato plano XR110/03, espaçados $0,50 \mathrm{~m}$ entre si, com pressão de trabalho de $45 \mathrm{lbf}$. $\mathrm{pol}^{-2}$, com volume de $200 \mathrm{~L}$ de calda por hectare.

A avaliação da fotossíntese líquida e condutividade estomática foram realizadas no ensaio 1 , aos 
37 e 74 dias após a emergência das plantas (DAE), com o aparelho LI 6400 Portable Photosynthesis System (LI - COR Bioscience Co.), equipamento portátil que realiza avaliações não destrutivas nas plantas através de um sistema com uma câmara de análise de variações de concentrações de $\mathrm{CO}_{2}$ conectada a um computador, conforme as instruções do fabricante.

Nos dois ensaios foi realizada a colheita das vagens e os parâmetros avaliados foram: número de vagens por planta, número de grãos por vagem e massa de 100 grãos. Para a determinação da massa seca de 100 grãos, estes foram secos em estufa com circulação forçada de ar, à temperatura de 55 ${ }^{\circ} \mathrm{C}$, durante sete dias, e aferido o peso em gramas.

Dois ensaios foram conduzidos em condições de campo, durante a safra das secas dos anos de 2007 e 2009, em uma propriedade agrícola localizada nas coordenadas geográficas longitude $48^{\circ}$ $22^{\prime} \mathrm{W}$ latitude $22^{\circ} 57^{\prime} \mathrm{S}$ e altitude de $893 \mathrm{~m}$, no município de Botucatu/SP de em solo arenoso de textura leve com condição climática classificada segundo Köeppen como Cwa. A cultivar de feijoeiro foi a Pérola, semeada na densidade de 15 sementes por metro linear em linhas espaçadas de 0,50 m. Cada parcela experimental foi constituída de seis linhas de cinco metros de comprimento. As práticas agronômicas utilizadas como preparo de solo, adubação e calagem, semeadura, condução da cultura basearam-se nas adotadas pelos produtores da região.

No primeiro experimento, conduzido na safra da seca de 2007, foi adotado o delineamento experimental em blocos ao acaso, com sete tratamentos e quatro repetições. Os produtos ensaiados foram: procimidone $-200 \mathrm{~g} \cdot \mathrm{ha}^{-1}$, metiran + piraclostrobina $825+75$ g.ha ${ }^{-1}$, piraclostrobina -75 g.ha ${ }^{-1}$, hidróxido de cobre - 1076 g.ha ${ }^{-1}$, tebuconazole - 40 g.ha ${ }^{-1}$, azoxistrobina -60 g.ha ${ }^{-1}$ e água (testemunha). No segundo experimento, conduzido na safra da seca de 2009, foi adotado o delineamento experimental em blocos ao acaso, com oito tratamentos e quatro repetições. Os produtos ensaiados foram: metiran + piraclostrobina $-825+75$ g.ha ${ }^{-1}$, piraclostrobina -75 g.ha ${ }^{-1}$, trifloxistrobina -150 g.ha ${ }^{-1}$, tebuconazole -40 g.ha ${ }^{-1}$, hidróxido de fentina -265 g.ha ${ }^{-1}$, tebuconazole + trifloxistrobina - 150+75 g.ha ${ }^{-1}$, azoxistrobina -60 g.ha $^{-1}$ e água (testemunha).

As pulverizações dos fungicidas foram realizadas aos 30, 45 e 60 após a semeadura, conforme proposto por Sartorato e Rava (1994), com um pulverizador costal pressurizado $\left(\mathrm{CO}_{2}\right)$, equipado com quatro pontas tipo jato plano XR110/03, espaçados 0,50 $\mathrm{m}$ entre si, e a uma altura aproximada de $0,50 \mathrm{~m}$ da superfície do solo, sob pressão de 45 lbf.pol ${ }^{-2}$ e volume de $400 \mathrm{~L}$ de calda de por hectare. No ensaio de 2007 foi adotado o delineamento experimental em blocos ao acaso, com sete tratamentos e quatro repetições e no ensaio de 2009 o mesmo delineamento experimental, com oito tratamentos e quatro repetições. Foi considerada área útil em ambos os ensaios as três linhas centrais de cada parcela, com comprimento de três metros, totalizando $4,5 \mathrm{~m}^{2}$.

Os parâmetros avaliados nos experimentos foram: severidade da mancha-angular em 20 folhas amostradas ao acaso no terço médios das plantas respeitando-se a área útil da parcela, atribuindo-se notas que variaram de 1 a 5 ( 1 - folha sem sintomas da doença; 2 - folha com até $12,5 \%$ da área foliar com sintomas da doença; 3 - folha entre $12,5 \%$ a $25 \%$ da área foliar com sintomas da doença; 4 folha entre $25 \%$ a $50 \%$ da área foliar com sintomas da doença e 5 - folha com mais de $50 \%$ da área foliar com sintomas da doença), aos 63, 70 e 77 dias após a semeadura, no ensaio 2007, e aos 67, 74,81 e 88 dias após a semeadura, no ensaio 2009 , porcentagem de vagens doentes (ensaio 2007), número médio de vagem por planta, massa de 100 grãos e número de grãos por vagem (ensaios 2007 e 2009). Com os dados da severidade da doença foi calculada a área abaixo da curva do progresso da doença (AACPD), conforme Schnider et al. (1976). Os valores obtidos dos diferentes parâmetros avaliados foram submetidos à análise de variância e as médias separadas pelo teste de Scott-Knott a 5\% de probabilidade. Os dados de porcentagem de vagens doentes foram transformados em arcsen $\sqrt{ } \mathrm{x} / 100 \mathrm{e}$ os de número médio de vagens por planta em $\sqrt{\mathrm{x}}$, para a análise de variância.

\section{Resultados e Discussão}

Na Tabela 1 são apresentados os resultados das avaliações da taxa fotossintética e da condutividade estomática das plantas de feijoeiro cultivar Pérola no ensaio conduzido no período de março a maio de 2010. Com base na primeira avaliação, aos 37 dias após a emergência, não houve diferença entre tratamentos quanto à taxa fotossintética das plantas pulverizadas com os diferentes fungicidas. Esse resultado não permaneceu estável, pois na avaliação efetuada aos 74 dias após a emergência, maiores 
valores foram obtidos para taxa fotossintética nos tratamentos piraclostrobina, tebuconazole e tebuconazole + trifloxistrobina que diferiram do tratamento testemunha. Os resultados aqui obtidos se assemelham aos de Fagan (2007), que detectou alterações dos níveis de fotossíntese com aplicação de piraclostrobina em soja, sob condições de campo. Entretanto, nos resultados aqui descritos pode- se observar que além da piraclostrobina, o tebuconazole e a sua mistura com trifloxistrobina apresentam esse efeito. Segundo Buchenauer (1995), fungicidas triazóis, e provavelmente o tebuconazole, promoverem alterações na morfologia das folhas, estimula o florescimento e a formação de frutos. Essa ação deve principalmente à inibição da biossíntese de giberelina, que promove o incremento do rendimento das culturas pelo aumento da resistência aos estresses ambientais (Rademacher, 1991). A redução desta biossíntese causa atraso na senescência da planta, o que permite a ela maior tempo com seu metabolismo de produção em condições adequadas. Outro efeito conhecido dos fungicidas triazóis refere-se à característica de reguladores de crescimento, conforme relatado nos trabalhos de Saishoji et al. (1998) em que o uso de tebuconazole promoveu a redução do porte das plantas e $o$ incremento da produção.

No caso dos resultados com a piraclostrobina, uma série de trabalhos relata a ação de fungicidas do grupo das estrobilurinas sobre o incremento de taxas de fotossíntese, redução dos processos de senescência das plantas, decréscimo da formação de etileno e de ácido abscíssico, ou o incremento da taxa de nitrogênio absorvido (Grossmann e Retzlaff, 1997; Grossmann et al., 1999; Oerke, 2001;.Venâncio et al., 2004)

Nenhum produto pulverizado alterou os índices de condutância estomática, sendo os mesmos similares à testemunha (Tabela 1). A redução dos valores de condutividade estomática com a aplicação de fungicidas do grupo das estrobilurinas foi relatada por Nason et al. (2007), Grossmann et al. (1999) e Veiga (2009). Esses dados são contraditórios aos obtidos por Fagan (2007) e aos obtidos neste experimento uma vez que as taxas de condutividade estomática (trocas gasosas) foram semelhantes para todos os tratamentos avaliados.

Não ocorreram em condições controladas grandes variações do número de vagens por plantas e número de grãos por vagem nos dois ensaios conduzidos com a aplicação dos diferentes fungicidas
(Tabela 2). Esses resultados são semelhantes aos obtidos por Barros et al. (2000), Sartorato e Rava (2003) e Veiga (2009) sob condições de campo, visando o controle da mancha angular em diversas cultivares de feijoeiro. Supõem que esses parâmetros sejam intrínsecos da cultivar sob condições normais sem serem afetados por agentes bióticos e abióticos.

No experimento conduzido no período de março a maio de 2010 (Tabela 2) os tratamentos piraclostrobina, hidróxido de fentina e tebuconazole + trifloxistrobina promoveram acréscimo no valor da massa seca de 100 grãos, entretanto essas observações não foram mantidas no segundo ensaio, conduzido no período de setembro a novembro de 2010 (Tabela 3). No segundo ensaio, apenas foi observado redução da massa de 100 grãos com a aplicação de tebuconazole sendo os demais tratamentos semelhantes à testemunha. Entretanto, Fagan et al. (2010) observaram efeito positivo no aumento da massa de 1000 grãos de soja com a aplicação de piraclostrobina ou tebuconazole, em campo, em relação ao tratamento testemunha. Acredita-se que as observações de Fagan et al. (2010) com piraclostrobina e tebuconazole tenham o fator controle de doença foliar (provavelmente a ferrugem asiática), no incremento da massa de grãos, pois sob condições normais de campo há a ocorrência de doenças em maior ou menor severidade.

As avaliações efetuadas nos ensaios conduzidos em campo, nas safras das secas de 2007 e 2009 encontram-se, respectivamente, nas Tabelas $4 \mathrm{e}$ 5. Conforme os dados observados da AACPD nos dois ensaios, nota-se claramente que a epidemia foi mais acentuada no ensaio realizado em 2007 do que em 2009.

Foram constatados menores valores da AACPD, conseqüentemente melhores efeitos no controle da mancha-angular nas folhas do feijoeiro cultivar Pérola para a pulverização dos fungicidas tebuconazole (Tabelas 4 e 5), azoxystrobina (Tabelas 4 e 5), metiram + piraclostrobina (Tabelas 4 e 5), piraclostrobina (Tabelas 4 e 5), hidróxido de fentina (Tabela 5) e tebuconazole + triflosxistrobina (Tabela 5) e valores mais elevados da AACPD, consequentemente menor eficácia no controle da doença nas folhas, para a aplicação de hidróxido de cobre, procimidone (Tabela 4) e trifloxistrobina (Tabela 5). As menores incidências de vagens com mancha angular foram obtidas com a aplicação de tebuconazole e metiram + piraclostrobina (Tabela 4). 
Tabela 1. Fotossíntese líquida e condutividade estomática de plantas de feijoeiro cultivar Pérola, pulverizadas com fungicidas. Ensaio 1 .

\begin{tabular}{lcccc}
\hline \multirow{2}{*}{ Fungicida } & \multicolumn{2}{c}{$\begin{array}{c}\text { Fotossíntese líquida } \\
\left(\text { micropmol. } \mathrm{CO}_{2} \cdot \mathrm{cm}^{-1} \cdot \mathrm{s}^{-1}\right)\end{array}$} & \multicolumn{2}{c}{$\begin{array}{c}\text { Condutividade estomática } \\
\left(\mathrm{mmol} \mathrm{m}^{-2} \mathrm{~s}^{-1}\right)\end{array}$} \\
\cline { 2 - 3 } & $37 \mathrm{DAE} 1$ & $74 \mathrm{DAE}$ & $37 \mathrm{DAE}$ & $74 \mathrm{DAE}$ \\
\hline Azoxistrobina & $16,32 \mathrm{a} 2$ & $5,23 \mathrm{~b}$ & $0,67 \mathrm{a}$ & $0,41 \mathrm{a}$ \\
Metiran + piraclostrobina & $14,30 \mathrm{a}$ & $5,04 \mathrm{~b}$ & $0,56 \mathrm{a}$ & $0,28 \mathrm{a}$ \\
Piraclostrobina & $15,32 \mathrm{a}$ & $8,94 \mathrm{a}$ & $0,85 \mathrm{a}$ & $0,48 \mathrm{a}$ \\
Trifloxistrobina & $16,32 \mathrm{a}$ & $5,08 \mathrm{~b}$ & $0,90 \mathrm{a}$ & $0,40 \mathrm{a}$ \\
Tebuconazole & $14,84 \mathrm{a}$ & $7,76 \mathrm{a}$ & $0,94 \mathrm{a}$ & $0,35 \mathrm{a}$ \\
Hidróxido de fentina & $14,44 \mathrm{a}$ & $4,67 \mathrm{~b}$ & $0,89 \mathrm{a}$ & $0,42 \mathrm{a}$ \\
Tebuconazole + trifloxistrobina & $13,91 \mathrm{a}$ & $11,76 \mathrm{a}$ & $0,58 \mathrm{a}$ & $0,58 \mathrm{a}$ \\
Testemunha (água) & $15,82 \mathrm{a}$ & $4,84 \mathrm{~b}$ & $0,60 \mathrm{a}$ & $0,26 \mathrm{a}$ \\
CV $(\%)$ & 22,30 & 49,67 & 60,8 & 49,9 \\
\hline
\end{tabular}

Dias após a emergência.

2 Médias seguidas da mesma letra não diferem entre si pelo teste de Scott-Knott a 5\% de probabilidade.

Tabela 2. Parâmetros agronômicos avaliados em plantas de feijoeiro cultivar Pérola, pulverizadas com fungicidas. Ensaio 1.

\begin{tabular}{lcccc}
\hline Fungicida & $\begin{array}{c}\mathrm{N}^{\circ} \text { vagem } \\
\text { por planta }\end{array}$ & $\begin{array}{c}\mathrm{N}^{\circ} \text { grão } \\
\text { por vagem }\end{array}$ & $\begin{array}{c}\text { Massa } 100 \\
\text { de grãos }(\mathrm{g})\end{array}$ & $\begin{array}{c}\text { Produção por } \\
\text { planta }(\mathrm{g})\end{array}$ \\
\hline Azoxistrobina & $14,30 \mathrm{a} 1$ & $4,93 \mathrm{a}$ & $33,95 \mathrm{~b}$ & $66,72 \mathrm{a}$ \\
Metiran + piraclostrobina & $16,70 \mathrm{a}$ & $4,79 \mathrm{a}$ & $34,96 \mathrm{~b}$ & $73,47 \mathrm{a}$ \\
Piraclostrobina & $15,61 \mathrm{a}$ & $4,57 \mathrm{a}$ & $35,79 \mathrm{a}$ & $67,71 \mathrm{a}$ \\
Trifloxistrobina & $15,16 \mathrm{a}$ & $5,04 \mathrm{a}$ & $33,22 \mathrm{~b}$ & $68,89 \mathrm{a}$ \\
Tebuconazole & $14,33 \mathrm{a}$ & $4,86 \mathrm{a}$ & $33,57 \mathrm{~b}$ & $60,04 \mathrm{a}$ \\
Hidróxido de fentina & $15,83 \mathrm{a}$ & $4,94 \mathrm{a}$ & $36,44 \mathrm{a}$ & $66,75 \mathrm{a}$ \\
Tebuconazole + trifloxistrobina & $15,89 \mathrm{a}$ & $4,91 \mathrm{a}$ & $38,35 \mathrm{a}$ & $69,92 \mathrm{a}$ \\
Testemunha (água) & $16,28 \mathrm{a}$ & $4,46 \mathrm{a}$ & $32,58 \mathrm{~b}$ & $70,21 \mathrm{a}$ \\
CV $(\%)$ & 11,41 & 13,09 & 6,83 & 10,07 \\
\hline
\end{tabular}

1 Médias seguidas da mesma letra não diferem entre si pelo teste de Scott-Knott a 5\% de probabilidade.

Tabela 3. Parâmetros agronômicos avaliados em plantas de feijoeiro cultivar Pérola, pulverizadas com fungicidas. Ensaio 2.

\begin{tabular}{lcccc}
\hline Fungicida & $\begin{array}{c}\mathrm{N}^{\circ} \text { vagem } \\
\text { por planta }\end{array}$ & $\begin{array}{c}\mathrm{N}^{\circ} \text { grão } \\
\text { por vagem }\end{array}$ & $\begin{array}{c}\text { Massa } 100 \\
\text { de grãos }(\mathrm{g})\end{array}$ & $\begin{array}{c}\text { Produção por } \\
\text { planta }(\mathrm{g})\end{array}$ \\
\hline Azoxistrobina & $14,73 \mathrm{a}$ & $3,56 \mathrm{a}$ & $28,07 \mathrm{a}$ & $33,79 \mathrm{a}$ \\
Metiran + piraclostrobina & $13,75 \mathrm{a}$ & $3,32 \mathrm{a}$ & $27,21 \mathrm{a}$ & $34,56 \mathrm{a}$ \\
Piraclostrobina & $14,25 \mathrm{a}$ & $3,71 \mathrm{a}$ & $27,83 \mathrm{a}$ & $33,83 \mathrm{a}$ \\
Trifloxistrobina & $12,58 \mathrm{a}$ & $3,39 \mathrm{a}$ & $28,83 \mathrm{a}$ & $36,64 \mathrm{a}$ \\
Tebuconazole & $15,08 \mathrm{a}$ & $3,27 \mathrm{a}$ & $22,96 \mathrm{~b}$ & $28,92 \mathrm{a}$ \\
Hidróxido de fentina & $12,99 \mathrm{a}$ & $3,27 \mathrm{a}$ & $26,33 \mathrm{a}$ & $36,33 \mathrm{a}$ \\
Tebuconazole+trifloxistrobina & $15,67 \mathrm{a}$ & $2,87 \mathrm{a}$ & $29,27 \mathrm{a}$ & $36,88 \mathrm{a}$ \\
Testemunha (água) & $11,66 \mathrm{a}$ & $3,30 \mathrm{a}$ & $27,04 \mathrm{a}$ & $37,75 \mathrm{a}$ \\
CV $(\%)$ & 12,65 & 15,28 & 8,12 & 12,71 \\
\hline
\end{tabular}

1 Médias seguidas da mesma letra não diferem entre si pelo teste de Scott-Knott a 5\% de probabilidade. 
Tabela 4. Efeito da pulverização de fungicida em feijoeiro cultivar Pérola no controle da mancha angular e sobre alguns parâmetros agronômicos. Safra das secas de 2007. Botucatu, SP.

\begin{tabular}{lcccc}
\hline Fungicida & AACPD & $\begin{array}{c}\text { \% vagem } \\
\text { doente }\end{array}$ & $\begin{array}{c}\mathrm{N}^{\circ} \text { vagem } \\
\text { por planta }\end{array}$ & $\begin{array}{c}\text { Massa } 100 \\
\text { grãos (g) }\end{array}$ \\
\hline Procimidone & $43,80 \mathrm{a} 1$ & $54,72 \mathrm{a}$ & $10,67 \mathrm{a}$ & $27,86 \mathrm{~b}$ \\
Metiran + piraclostrobina & $36,21 \mathrm{~b}$ & $37,32 \mathrm{~b}$ & $11,65 \mathrm{a}$ & $30,06 \mathrm{a}$ \\
Piraclostrobina & $38,96 \mathrm{~b}$ & $57,09 \mathrm{a}$ & $12,72 \mathrm{a}$ & $29,44 \mathrm{a}$ \\
Hidróxido de cobre & $43,80 \mathrm{a}$ & $67,60 \mathrm{a}$ & $12,10 \mathrm{a}$ & $27,47 \mathrm{~b}$ \\
Tebuconazole & $26,55 \mathrm{c}$ & $37,89 \mathrm{~b}$ & $12,30 \mathrm{a}$ & $31,03 \mathrm{a}$ \\
Azoxistrobina & $36,86 \mathrm{~b}$ & $56,17 \mathrm{a}$ & $12,47 \mathrm{a}$ & $28,23 \mathrm{~b}$ \\
Testemunha (água) & $45,07 \mathrm{a}$ & $65,56 \mathrm{a}$ & $12,65 \mathrm{a}$ & $27,17 \mathrm{~b}$ \\
CV\% & 9,90 & 16,85 & 15,27 & 4,38 \\
\hline
\end{tabular}

1 Médias seguidas da mesma letra não diferem entre si pelo teste de Scott-Knott a 5\% de probabilidade.

Tabela 5. Efeito da pulverização de fungicida em feijoeiro cultivar Pérola no controle da mancha angular e sobre alguns parâmetros agronômicos. Safra das secas de 2009. Botucatu, SP.

\begin{tabular}{|c|c|c|c|c|}
\hline Fungicida & AACPD & $\begin{array}{l}\mathrm{N}^{\circ} \text { vagem } \\
\text { por planta }\end{array}$ & $\begin{array}{c}\mathrm{N}^{\mathrm{o}} \text { grão } \\
\text { por vagem }\end{array}$ & $\begin{array}{c}\text { Massa } 100 \\
\text { grãos }(\mathrm{g})\end{array}$ \\
\hline Azosistrobina & 26,86 b1 & $12,88 \mathrm{a}$ & $4,46 \mathrm{a}$ & $34,75 \mathrm{a}$ \\
\hline Metiran + piraclostrobina & $25,54 \mathrm{~b}$ & 16,67 a & $4,60 \mathrm{a}$ & $34,25 \mathrm{a}$ \\
\hline Piraclostrobina & $24,01 \mathrm{~b}$ & $12,78 \mathrm{a}$ & $4,96 \mathrm{a}$ & $32,00 \mathrm{a}$ \\
\hline Triflosxistrobina & 27,89 a & $15,41 \mathrm{a}$ & $4,77 \mathrm{a}$ & $33,50 \mathrm{a}$ \\
\hline Tebuconazole & $25,22 \mathrm{~b}$ & $14,70 \mathrm{a}$ & $4,63 \mathrm{a}$ & $34,00 \mathrm{a}$ \\
\hline Hidróxido de fentina & $24,21 \mathrm{~b}$ & $13,14 \mathrm{a}$ & $4,66 \mathrm{a}$ & $33,50 \mathrm{a}$ \\
\hline Tebuconazole + trifloxistrobina & $24,81 \mathrm{~b}$ & $13,71 \mathrm{a}$ & $4,96 \mathrm{a}$ & $33,25 \mathrm{a}$ \\
\hline Testemunha (água) & $30,91 \mathrm{a}$ & 13,86 a & $4,91 \mathrm{a}$ & $32,00 \mathrm{a}$ \\
\hline $\mathrm{CV}(\%)$ & 8,79 & 16,64 & $10,59 \mathrm{a}$ & 5,62 \\
\hline
\end{tabular}

1 Médias seguidas da mesma letra não diferem entre si pelo teste de Scott-Knott a 5\% de probabilidade.

Os resultados aqui observados para o controle da doença com tebuconazole, azoxistrobina e piraclostrobina são concordantes com os resultados de outros trabalhos desenvolvidos no Brasil e no exterior (Barros et al., 2000; Ito et al., 2000; Rava, 2002, Celetti et al., 2005). A baixa eficácia da trifloxistrobina, aplicada isoladamente, no controle da doença aqui observada vai ao encontro dos resultados obtidos por Sartorato (2006), que sugeriu a mistura de trifloxistrobina com tebuconazole ou protioconazole para melhorar a eficácia desse fungicida no controle da mancha-angular.

Conforme consta na Tabela 5, o hidróxido de fentina teve ação no controle da mancha-angular nas folhas. Alguns trabalhos indicam o uso deste fungicida em mistura com diferentes ingredientes ativos (tebuconazole, carbendazin + fluquinconazole e propiconazole), conforme Barros e Castro. (1999), Ito et al. (2000), Oliveira (2003), para o controle da doença. Embora o hidróxido de cobre, na dosagem utilizada apresentou baixa eficácia de controle (Tabela 4), há a indicação do seu uso para esse fim, quando aplicado de forma alternada com outros ingredientes ativos de fungicida (Sartorato, 2006). Com relação ao procimidone, com baixa eficácia no controle da mancha angular aqui relatado, é indicado no controle do mofo-branco em feijoeiro (Venegas e Saad, 2010; Agrofit, 2011).

Com relação aos parâmetros agronômicos aqui avaliados, concordantes com Barros e Castro (1999) e Sartorato e Rava (2003), não foi constatado o efeito da aplicação dos diferentes fungicidas quanto ao número de vagens por planta e número de grãos por vagem (Tabelas 5). Porém foi observado efeito na massa de 100 grãos (Tabela 4), principalmente para aqueles produtos que apresentaram melhor eficácia no controle da mancha angular, em condições de epidemia mais acentuada da doença. Trabalhos 
desenvolvidos por Oliveira (2003), Vieira (2004) e Canteri e Godoy (2005) evidenciaram relação direta na eficácia do controle da mancha angular com produtividade do feijoeiro. Segundo Bassanezi et al. (2001), a severidade da mancha angular está diretamente relacionada à redução dos níveis de clorofila e fotossíntese nos tecidos, por consequiência, quanto melhor o controle da doença na parte aérea da planta, maior a produtividade do feijoeiro, fato este observado no presente trabalho em condição de epidemia mais severa, para os tratamentos que obtiveram menores valores da AACPD os quais apresentaram maior massa de 100 grãos, excetuando-se a azoxistrobina (Tabela 4).

\section{Literatura Citada}

\section{AGROFIT}

2011 Sistema de agrotóxicos fitossanitários. Brasília: Ministério da Agricultura, Pecuária e Abastecimento. Disponível em: http://extranet.agricultura.gov.br/agrofit_cons/principal_agrofit_cons. Acesso em 14 jul. 2011.

Barros, B.C.; Castro, J.L.

1999 Eficiência de fungicidas no controle da mancha angular (Phaeoisariopsis griseola) do feijoeiro comum (Phaseolus vulgaris L.). In: Reunião Nacional de Pesquisa de Feijão, 6., 1999, Salvador. Resumos Expandidos. Santo Antonio de Goiás: Embrapa Arroz e Feijão. pp. 182-184. (Embrapa Arroz e Feijão. Documentos, 99).

Barros, B.C.; Oliveira, S.H.F.; Leite, L.G.; Ito, M.F.; Campos, T.B.; Oliveira, C.M.G.; Sannazzarro, A.M; Castro, J.L.; Pinzan, N.R. 2000. Manejo integrado de pragas e doenças do feijoeiro. Campinas: CATI, 90 p. (Manual Técnico, 3).

Bassanezi, R.B.; Amorim, L.; Bergamin Filho, A.

2001. Eficiência fotossintética de folhas de feijoeiro infectadas com o vírus do mosaico-em desenho, Uromyces appendiculatus e Phaeoisariopsis griseola. Summa Phytopathologica, 27 (1): 05-11.

Buchenauer, $\mathrm{H}$.

1995 DMI-fungicides side effects on the plant and problems of resistance. In: Lyr, H. (Ed.). Modern selective Fungicides: properties, applications, mechanisms of action. $2^{\text {nd }}$ ed. New York; Jena: Gustav Fischer Verlag, Chap.13, 259-290.

Canteri, M.G.; Godoy, C.V.

2005 Eficiência fotossintética da área foliar saudável influenciado pela severidade da mancha angular no campo de feijão. Semina: Ciências Agrárias (Londrina), 26 (2): 179-186.

Celetti, M.J.; Melzer, M.S.; Boland, G.J.

2005 Integrated management of angular leaf spot (Phaeoisariopsis griseola (Sacc.) Ferr.) on snap beans in Ontario. Plant Health Progress, November, pp. 1-8.

Del Peloso, M.J.; Costa J.G.C.; Rava C.A.; De Faria, L.C. 2003 Cultivo do feijoeiro comum. Embrapa Arroz e Feijão Sistemas de Produção, 2. Jan 2003. Disponível em: http// sistemasdeproduçao.cnptia.embrapa.br/FontesHTML/Feijao/ Cultivodofeijoeiro/cultivares.htm. Acesso em 14 nov. 2011.

Fagan, E.B;

2007 A cultura da soja: Modelo de crescimento e aplicação da estrobirulina piraclostrobina. 84 p. Tese de Doutorado, Escola Superior de Agricultura Luiz de Queiroz, USP, Piracicaba.

Fagan, E.B.; Dourado Neto D.; Vivian R.; Franco, R.B.; Yeda, M.P.; Massignam, L.F.; Oliveira, R.F.; Martins, K.V.

2010. Efeito da aplicação de piraclostrobina na taxa fotossíntética, respiração, atividade da enzima nitrato redutase e produtividade de grãos de soja. Bragantia, 69 (4): 771-777.
FAOSTAT Agricultural statistics database

2007 World Agricultural Information Centre. Disponível em: <http://apps.fao.org/ >. Acesso em: 14 jul. 2011.

Grossmann, K.; Kwiatkowski, J.; Caspar, G.

1999 Regulation of phytormone levels leaf senescence and transpiration by the strobilurin kresoxim methyl in wheat (Triticum aestivum) Journal of Plant Physiology 154, (5-6): 805-808.

Grossman,K.; Retzlaff, G.

1997 Bioregulatory effects of the fungicidal strobilurin Kresoxim methyl in wheat (Triticum aestivum L.). Pesticide Science 50 (1): 11-20.

Ito, M.F; Bergamin Filho, A.; Yuki, V.A.

1994 Efeito do fungicida cartap sobre a mancha angular do feijoeiro. Fitopatologia Brasileira 19 (supl.): 288-289.

Ito, M.F.; Castro, J.L.; Peterrossi Jr., N.; Ito, M.A.

2000 Eficiência do trifenil hidróxido de estanho e associações no controle da antracnose, mancha de Alternaria e oídio do feijoeiro. Fitopatologia Brasileira 25 (supl.): 381.

Kendra, V.K.; Sdhukla, A.; Silva, H.R.

2009 Management fungicides for control angular spot and rust on dry beans. Journal of Science Disease Vegetal 4: 222-223.

Nason, M.A.; Farrar, J.; Bartlett, D.

2007 Strobirulin fungicides induce change in photosynthetic gas exchange that do not improve water efficiency of plants grown under conditions of water stress. Pest Management Science 63 (12): 1191-1200.

Oerke, M.A.; Beck, C.; Dehne, H.W.

2001 Physiologic effects of strobirulins on wheat yield. Phytopathology .91 (supl. 6): S67.

Oliveira; S.H.F.

2003 Novos fungicidas e programas de pulverização par o controle da antracnose e mancha angular da do feijoeiro. Summa Phytopathologica 29 (1): 45-48.

Rademacher, W.

1991 Inhibitors of gibberellin biosynthesis: Applications in agriculture and horticulture. In Takahashi, N.; Phinney, B.; Macmillan, J.(Ed). Gibberelins. New York. Springer-Verlag, pp. 296-310.

Rava, C.A..

2002 Eficiência de fungicidas no controle da antracnose e da mancha angular do feijoeiro comum. Summa Phytopathologica 28 (1): 65-69.

Rodrigues, M.A.T.; Begliomini, E.; Dourado-Neto, D. 2009 Efeito fisiológico da piraclostrobina em plantas de feijão. Tropical Plant Pathology 34 (supl.): 394.

Saettler, A.W.

1994 Angular leaf spot. In: HALL, R. (ed). Compendium of bean disease, St.Paul: The American Phytopatological Society, pp. 15-16. 
Saishoji, T.; Ito. A.; Kumazawa, S.; Chuman, H.

1998 Structure-activity relationships of enantiomers of the azole fungicide ipconazole and its related compounds: fungicidal and plant growth inhibitory activities. Journal of Pesticide Science 23 (2): 129-136.

Sartorato, A.; Rava, C.A.

1994 Mancha angular. In: Sartorato, A.; Rava, C.A. (org.). Principais doenças do feijoeiro comum e seu controle. Goiânia: EMBRAPA - CNPAF, pp. 41-89.

Sartorato, A.; Rava, C.A.

2003 Controle químico da mancha-angular do feijoeiro. Summa Phytopathologica 29 (2): 202-204.

Sartorato, A.

2006 Controle químico da mancha angular do feijoeiro comum. Goiânia: Embrapa Arroz e Feijão. 3 p. (Comunicado Técnico, 118).

Schneider, R.W.; Williams, R.J.; Sinclair, J.B.

1976 Cercospora leaf spot of cowpea: models for estimating yield loss. Phytopathology 66 (4): 384-388.
Venâncio, W.S.; Rodrigues, M.A.T.; Begliomini, E.; Souza, N.L. 2004 Physiological effects of strobilurin fungicides on plants. Publicatio UEPG. Ponta Grossa. 9 (3): 59-68.

Venegas F; Saad, J.C.C.

2010 Fungigação no controle do mofo branco e produtividade do feijoeiro em condições de cerrado brasileiro. Irriga 15 (2): 159-172.

Veiga, J.S.

2009 Análise dos efeitos secundários decorrentes da aplicação de fungicidas sistêmicos à cultura do feijoeiro ( Phaseolus vulgaris). Dissertação de Mestrado, 100 p. Escola Superior de Agricultura Luiz de Queiroz, USP, Piracicaba, SP.

Vieira, R.F.

2004 Aumento do rendimento causado pela aplicação de fungicidas em feijoeiro comum com diferentes graus de resistência a doença. Revista Ceres 51 (295): 355-366. 